\title{
An Empirical Comparative Study of Renewable Biochar and Fossil Carbon as Carburizer in Steelmaking
}

\author{
Ryan ROBINSON, (1* Liviu BRABIE, ${ }^{1)}$ Magnus PETTERSSON, ${ }^{1)}$ Marko AMOVIC ${ }^{2)}$ and Rolf LJUNGGREN ${ }^{2)}$ \\ 1) Höganäs $A B$, Höganäs, 23683 Sweden. \\ 2) Cortus Energy AB, Kista, 16440 Sweden.
}

(Received on March 10, 2020; accepted on May 18, 2020; J-STAGE Advance published date: August $27,2020)$

\begin{abstract}
Approximately $60-70 \%$ of the direct greenhouse gas emissions in electric arc furnace (EAF) steelmaking originate from the use of fossil carbon charge during melting of steel scrap. Regarding short-term solutions to mitigate the climate impact of steelmaking, there is greater potential to replace fossil carbon charge with renewable carbon in the EAF than in integrated blast furnace steelmaking where mechanical strength requirements on carbon charge are too demanding. Therefore, the present study aims to provide an experimental and practical foundation for using renewable biochar in the EAF as a relatively simple step to decrease the climate impact of steelmaking.

In order to evaluate the inherent performance of biochar as a carburizing agent, lab-scale tests where completed using four different types of carbonaceous materials: synthetic graphite, anthracite coal and two types of biochar from woody biomass (BC1 and BC2). The first order dissolution rate constants from experiments ranged between 0.7 to $1.9 \times 10^{-4} \mathrm{~m} / \mathrm{s}$, which agrees well with previously reported results. Furthermore, lab-scale results show that biochar properties commonly seen as detrimental, such as low carbon crystallinity and high porosity, do not necessarily constitute a disadvantage for biochar utilization as carburizer in steelmaking.

In order to further assess the results from lab-scale tests, an industrial trial including six consecutive heats was performed in a $50 \mathrm{t}$ EAF at the Höganäs Halmstad Plant. Results show that 33\% substitution of standard Anthracite carbon charge with biochar BC2 gave no deviation from normal operating conditions in the EAF.
\end{abstract}

KEY WORDS: greenhouse gas emissions; renewable biochar; anthracite; carbon dissolution rate; liquid iron; EAF; carbon yield; ash content.

\section{Introduction}

In early 2018, the newly established Swedish Climate Act set some ambitious climate targets among which the most defining is a long term goal to reach net-zero greenhouse emissions on a national level by 2045 . Sweden's total greenhouse emissions were 52.7 million metric tons in 2017 , of which $11.8 \%$ originated from the iron and steelmaking industry. ${ }^{1,2)}$ The majority of direct greenhouse gas emissions in iron and steelmaking come from fossil-based process coal and coke used as fuel and reduction agent in blast furnaces, but not to be dismissed are also the sizeable emissions that originate from fossil carbon consumption during melting of steel scrap in electric arc furnaces. Furthermore, greenhouse emissions from EAF steelmaking are likely to increase as the share of global crude steel production via the EAF is predicted to grow substantially over the coming decades. ${ }^{3)}$ In the EAF, carbon charge serves three purposes; as an additional energy source, as a slag foaming agent and most intuitively as an alloying element in molten iron to produce

* Corresponding author: E-mail: ryan.robinson@hoganas.com DOI: https://doi.org/10.2355/isijinternational.ISIJINT-2020-135 steel. Carbon charge in the form of fossil coal, coke or graphite accounts for $40-70 \%$ of the direct greenhouse gas emissions from the EAF and thereby replacement of these fossil materials with renewable coal based on biomass is seen as one of the most promising ways to reduce greenhouse gas emissions in steelmaking. ${ }^{4,5)}$

The mechanism of carbon dissolution is of importance for efficient steelmaking in the EAF. The chemical composition and concentration of ash in carbon charge has been found to have a significant influence on the rate of carbon dissolution. ${ }^{6)}$ Ash can form an interfacial layer between molten iron and carbonaceous materials during carbon dissolution, which can cause interface blockage and a reduction in the effective contact area for carbon dissolution in iron melts. In addition, carbon materials with higher porosity could trap liquid iron in its pores creating islands of iron saturated with carbon, further limiting the area available for progression of carbon dissolution. ${ }^{7)}$

In the EAF, carbon is commonly fed to the furnace via the scrap bucket in the form of primary carbon units such as anthracite/pet coke but also as bound carbon in alternative iron units such as DRI, HBI, and pig iron. Typically, carbon consumption is in the range of 3 to $12 \mathrm{~kg}$ per tonne liquid 
steel with a recovery rate in the range of $30-80 \%$ depending on the particle size and method of addition. ${ }^{8}$ As a consequence, low carbon recovery in the EAF correlates directly with iron yield loss to the slag and therefore there is a need for understanding the specific carbon dissolution mechanisms for each type of carbon containing raw material. Production and use of biochar in ironmaking and to some extent steelmaking has been reviewed by various authors and results from recent studies show that biochars can be suitable for at least partial substitution of fossil carbon in the EAF. ${ }^{4,9)}$ Furthermore, numerous studies have been conducted to investigate the carburization behavior of different types of carbonaceous materials in molten iron at conditions relevant for ironmaking, i.e. molten $\mathrm{Fe}-\mathrm{C}$ alloy temperature $<1823 \mathrm{~K}$ and starting carbon contents $>2 \%{ }^{6,9,14-16)}$ On the other hand, there is a lack of information in the literature concerning the intrinsic behavior of biochar contra conventional fossil carbon materials as carburizer in $\mathrm{Fe}-\mathrm{C}$ alloy at steelmaking conditions, i.e. temperature $>1823 \mathrm{~K}$ and starting carbon contents $<2 \%$.

Therefore, the present study aims to provide a theoretical, experimental and practical foundation for using biochar in EAF steelmaking. Thereof, comparative carburization trials have been completed for different materials in a lab-scale furnace as basis for a subsequent preliminary large-scale trial in Höganäs Halmstad's production unit.

\section{Materials and Experimental Procedure}

\subsection{Lab-scale Carburizing Trials}

In order to evaluate the inherent performance of biochar as a carburizing agent, a comparison has been made with conventional materials used in the EAF. Four different types of carbonaceous materials were used in this study: synthetic graphite, anthracite coal and two types of biochar from woody biomass (BC1 and $\mathrm{BC} 2)$. Biochar $\mathrm{BC} 1$ is based on commercial wood chips made from logging residues and $\mathrm{BC} 2$ is based on commercial wood pellets made from sawdust.

\section{Charcoal in}

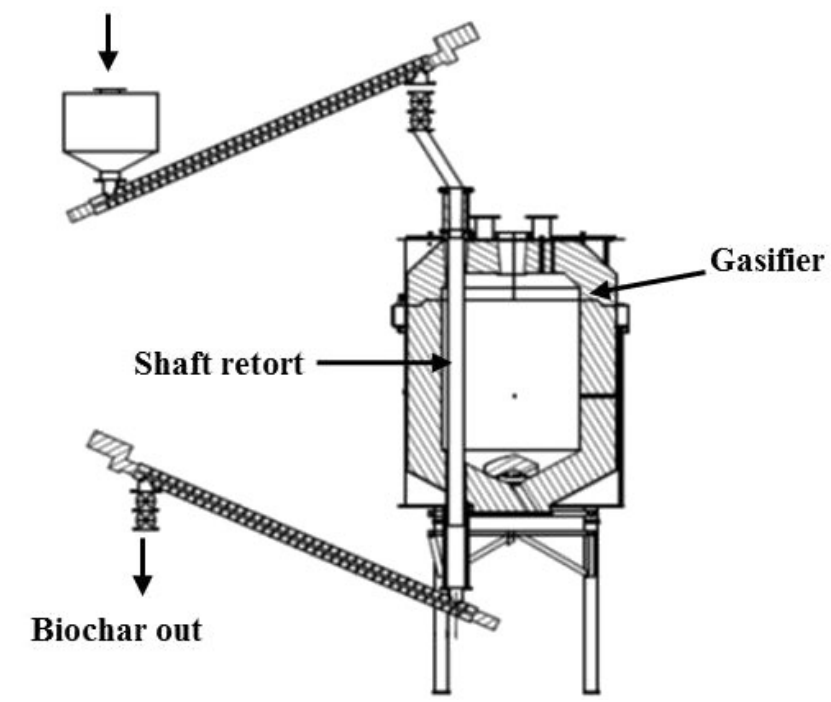

Fig. 1. WoodRoll ${ }^{\circledR}$ biomass gasifier with shaft retort for biochar production.
The biochar materials in this study were prepared using an experimental method based on a patented novel method of high temperature biomass gasification called WoodRoll ${ }^{\circledR}$. In this process, charcoal is produced from biomass via slow pyrolysis at $623-673 \mathrm{~K}$ followed by a separate heattreatment of charcoal at $1373 \mathrm{~K}$ to produce the biochar. Normally, the biochar is gasified via reaction with pressurized steam to produce syngas, but in this study the process was modified to produce exclusivley biochar in the absence of steam injection.

For pilot-scale biochar production, pyrolysis was performed on pre-dried biomass in a rotary drum type reactor using residence times greater than 45 minutes. After pyrolysis, the charcoal was fed to an indirectly heated shaft retort located inside the gasification reactor to produce biochar, see Fig. 1. This "coking" treatment occurred in inert gas atmosphere for residence times between 10 and 30 minutes.

Analyses of the different carbonaceous materials used in lab-scale trials are presented in Tables $\mathbf{1}$ and 2. As-received carbonaceous materials had large differences in particle size distribution, therefore all materials were milled for homogenizing purposes and only material passing a $45 \mu \mathrm{m}$ sieve was used in lab-scale trials. A Sympatec particle analyzer was used to evaluate the particle size distribution of the different materials. Apparent densities were measured by fill-

Table 1. Proximate analysis and physical properties of the different carbonaceous materials.

\begin{tabular}{ccccc}
\hline & Graphite & Anthracite & BC 1 & BC 2 \\
\hline Volatile (wt\%) & - & 2.7 & 14 & 8.8 \\
C-fix (wt\%) & 99.95 & 92.4 & 72.3 & 89.8 \\
Ash (wt\%) & 0.05 & 4.9 & 13.7 & 1.4 \\
S (wt\%) & 0.0013 & 0.125 & 0.012 & 0.012 \\
\hline $\mathrm{d} 50(\mu \mathrm{m})$ & 18.3 & 14.7 & 14.4 & 16.4 \\
$\mathrm{~d} 10(\mu \mathrm{m})$ & 5.2 & 2.6 & 3.1 & 4.3 \\
$\mathrm{~d} 90(\mu \mathrm{m})$ & 37.9 & 35.5 & 32.9 & 44.9 \\
\hline $\begin{array}{c}\text { Apparent Density } \\
\left(\mathrm{g} / \mathrm{cm}^{3}\right)\end{array}$ & 0.22 & 0.42 & 0.27 & 0.41 \\
\hline $\begin{array}{c}\text { Avg. True Density } \\
\left(\mathrm{g} / \mathrm{cm}^{3}\right)\end{array}$ & $2.26 \pm 0.007$ & $1.81 \pm 0.003$ & $1.77 \pm 0.008$ & $1.57 \pm 0.005$ \\
\hline
\end{tabular}

Table 2. Chemical composition of ash in the different carbonaceous materials.

\begin{tabular}{cccc}
\hline $\mathrm{wt}_{0}$ & Anthracite & $\mathrm{BC} \mathrm{1}$ & $\mathrm{BC} \mathrm{2}$ \\
\hline $\mathrm{SiO}_{2}$ & 44.31 & 19.13 & 14.30 \\
$\mathrm{Al}_{2} \mathrm{O}_{3}$ & 24.90 & 10.66 & 2.63 \\
$\mathrm{CaO}$ & 4.48 & 63.33 & 38.07 \\
$\mathrm{Fe}_{2} \mathrm{O}_{3}$ & 20.12 & 2.58 & 9.22 \\
$\mathrm{~K}_{2} \mathrm{O}$ & 2.19 & 1.33 & 19.53 \\
$\mathrm{MgO}$ & 1.77 & 2.06 & 7.20 \\
$\mathrm{Mn}_{3} \mathrm{O}_{4}$ & 0.25 & 0.32 & 4.76 \\
$\mathrm{Na}_{2} \mathrm{O}$ & 0.70 & 0.41 & 0.87 \\
$\mathrm{P}_{2} \mathrm{O}_{5}$ & 0.65 & 0.17 & 3.02 \\
$\mathrm{ZnO}$ & 0.65 & 0.02 & 0.41 \\
\hline
\end{tabular}


ing a cup of know volume and recording the mass for each material andaverage true densities were measured using a AccuPyc II 1340 He gas displacement pycnometer.

Figure 2 shows SEM images of the different carbonaceous materials. As one can see, there are obvious distinctions in the shape of particles between the materials. Anthracite and $\mathrm{BC} 2$ are more granular in form while graphite and $\mathrm{BC} 1$ are more in the form of flakes. These images help to explain the differences in apparent density seen in Table 1. Furthermore, some biochar particles show signs of high internal porosity as a remnant of woody biomass cell structure; see circled area in Fig. 2(d). Higher porosity in biochar, especially $\mathrm{BC} 2$, is also evident by the lower values for average true density shown in Table 1 .

\subsubsection{Briquetting of the Samples}

The carbonaceous materials were pressed into briquettes together with iron flakes in order to better facilitate full immersion of samples in the metal bath. A mixture of $16 \%$ carbonaceous material, $80 \%$ iron flakes and 4\% wax binder was found to give satisfactory handling strength. The materials were homogenized using a laboratory orbiting screw mixer with a mixing time of 15 minutes. Briquettes were produced at room temperature in a hydraulic Mohr press at $200 \mathrm{MPa}$ using a cylindrical press mold and an extrusion die of $32 \mathrm{~mm}$ diameter. The mean weight of briquettes was $100 \mathrm{~g}$ and their general dimensions are presented in Fig. 3.

\subsubsection{Equipment}

Experiments to study the dissolution rates of carbona- ceous materials were carried out in $10 \mathrm{~kg}$ melts of ironcarbon alloys contained in a pure alumina crucible of 120 $\mathrm{mm}$ inner diameter and $257 \mathrm{~mm}$ height. The iron-carbon melts $(0.2 \% \mathrm{C})$ were prepared in a $30 \mathrm{~kW} / 3 \mathrm{kHz}$ induction furnace by melting a mixture of pure metallic iron flakes (same as in briquettes) and cast iron, chemical analysis is presented in Table 3. The experimental furnace setup employed in the present investigations is shown in Fig. 4. The furnace temperatures were monitored continuously

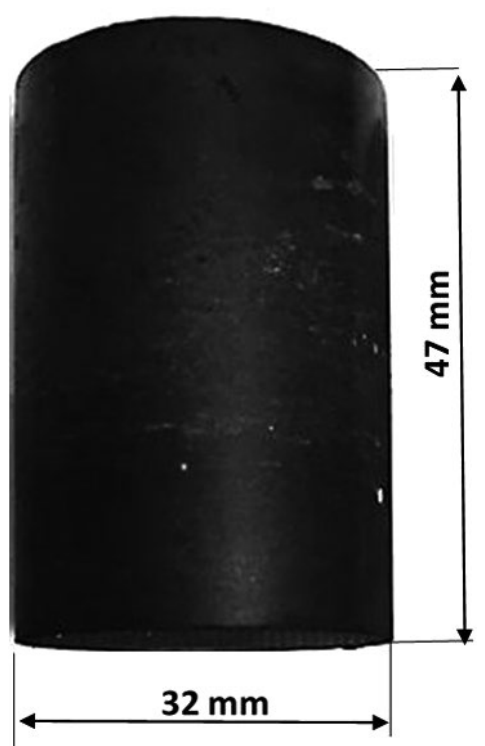

Fig. 3. Briquette dimensions.
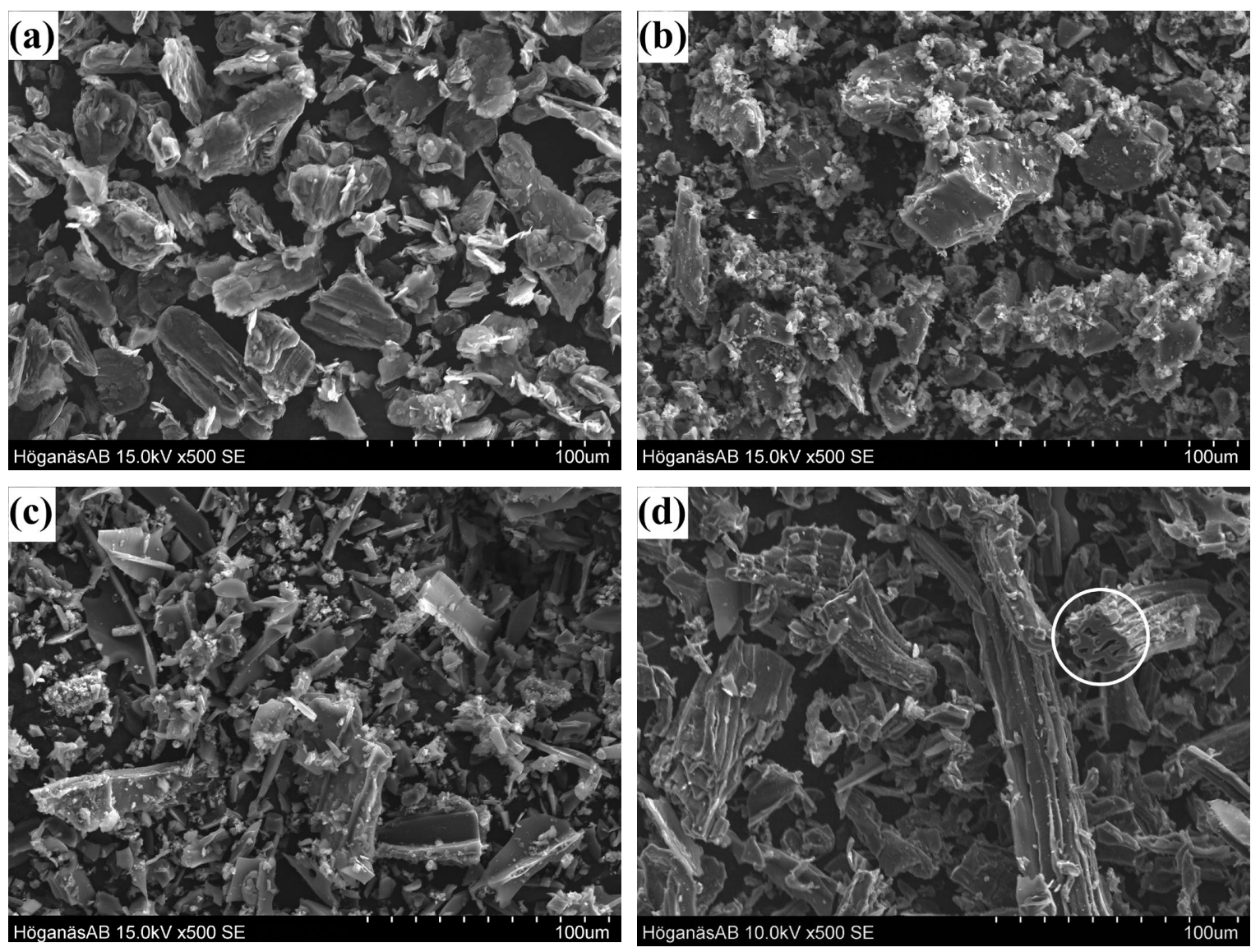

Fig. 2. SEM pictures of a) Graphite b) Anthracite c) BC1 d) BC2. 
Table 3. Chemistry of the iron flakes and granulated cast iron used as raw material.

\begin{tabular}{ccc}
\hline $\mathrm{wt} \%(\mathrm{Fe}$ base $)$ & Iron flakes & Granulated cast iron \\
\hline $\mathrm{Al}$ & 0.078 & - \\
$\mathrm{Cr}$ & 0.016 & 0.037 \\
$\mathrm{Cu}$ & $<0.001$ & 0.01 \\
$\mathrm{Mn}$ & 0.03 & 0.24 \\
$\mathrm{Mo}$ & $<0.001$ & 0.003 \\
$\mathrm{Ni}$ & 0.013 & 0.032 \\
$\mathrm{P}$ & 0.003 & 0.036 \\
$\mathrm{Si}$ & 0.054 & 0.65 \\
$\mathrm{Sn}$ & $<0.001$ & - \\
$\mathrm{Ti}$ & 0.092 & 0.14 \\
$\mathrm{~V}$ & 0.083 & 0.29 \\
$\mathrm{C}$ & 0.01 & 4.443 \\
$\mathrm{~S}$ & 0.0042 & 0.029 \\
$\mathrm{O}$ & 0.4252 & - \\
\hline
\end{tabular}

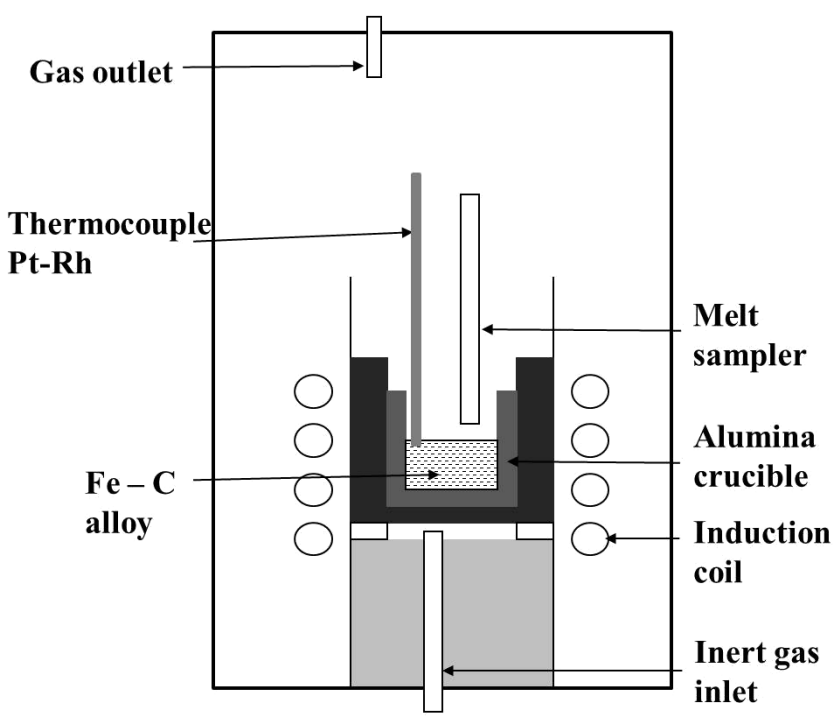

Fig. 4. Experimental lab-scale furnace set-up.

using a type-B thermocouple which was placed in a molybdenum-zirconia rod inside the melt.

\subsubsection{Experimental Procedure}

The furnace chamber was degassed to $50 \mathrm{mBar}$ and oxygen levels below 100 ppm using a vacuum pump, and then nitrogen gas was introduced into the furnace. During all trials, a positive pressure of inert gas inside the furnace chamber of 3-15 mBar was maintained. When the melt temperature reached the desired experimental temperature of $1873 \mathrm{~K}$, a first sampling of the iron-carbon alloy was carried out to confirm the initial composition of the melt. Then five briquettes of $100 \mathrm{~g}$ each were added. Power to the furnace was increased momentarily to compensate for a temperature loss of roughly $50 \mathrm{~K}$ during charging. Metal samples were taken every 30 seconds. After 150 seconds another five briquettes were added and metal samples taken every 30 seconds. Two dissolution tests were performed for each carbonaceous material.

\subsection{Large-scale Trial at Höganäs Halmstad}

In order to verify the results obtained with biochar from lab-scale tests, a trial including six consecutive heats was performed in the $50 \mathrm{t}$ EAF at Höganäs AB Halmstad Plant. The aim of the trial was to compare the performance of biochar to anthracite by replacing $1 / 3$ of the standard anthracite charge with biochar in three of the six heats.

For Halmstad plant operations in the EAF, the first carbon sample is targeted to be in the range of $0.05-0.35 \%$ based on the desired alloy chemistry. Carbon units are charged in the range of $600-800 \mathrm{~kg}$ via a combination of carboncontaining alternative iron units, i.e. pig iron and DRI, and carbonaceous materials, i.e. anthracite and petcoke, to obtain the required carbon value for each grade. For these trials, the available grades normally used in the scrap mix were limited to minimize density and chemistry variations between melts. The melt praxis entails that 2 scrap buckets are charged for each melt with the carbonaceus material added in the first bucket.

Around $600 \mathrm{~kg}$ of carbonaceous material was split equally in 3 bags. In the three reference heats, 3 bags containing 200 $\mathrm{kg}$ of anthracite each were charged in each heat while in the other three heats, two bags of $200 \mathrm{~kg}$ anthracite plus one bag of $200 \mathrm{~kg}$ biochar were charged. The bags were deliberately placed in the middle of the first scrap bucket in order to avoid submerging them directly in the hot heel of the furnace which should minimize premature loses of biochar due to its higher combustibility relative to anthracite. The following conditions were applied to all heats during the trial:

- Same amount of slag formers.

- Second scrap basket was charged at $200 \mathrm{kWh} / \mathrm{t}$

- Oxygen injection $\left(\max 50 \mathrm{Nm}^{3}\right)$ only between 300 to $450 \mathrm{kWh} / \mathrm{t}$

- First carbon sample was taken at $500 \mathrm{kWh} / \mathrm{t}$

- Carbon lance injection was not used until after the first carbon sample was taken

\section{Result and Discussion}

\subsection{Lab-scale Carburizing Trials}

Carbon dissolution trials were conducted with briquettes containing samples of synthetic Graphite, Anthracite coal, Biochar 1 (BC1) and Biochar 2 (BC2). Figure 5 show the changes in carbon and sulfur content of the iron bath over time for the different samples. The method of charging 5 briquettes in two successive charges was applied as a compromise between having sufficient time to sample the melt before carbon dissolution ceased meanwhile causing as minimal cooling effect to the melt as possible. The first 5 briquettes were charged at $\mathrm{t}=0$ and the second 5 briquettes were charged at $\mathrm{t}=150 \mathrm{sec}$. Even though each trial was allowed to proceed for 5 minutes, the majority of carbon dissolution was completed within 30 seconds for each charge. Therefore, reported k' values in Table $\mathbf{4}$ are an average of the slopes generated between times $0-30$ seconds and 150-180 seconds in Fig. 6.

A widely accepted ${ }^{7,10-13)}$ first order kinetic equation was used to describe the apparent carbon dissolution, 

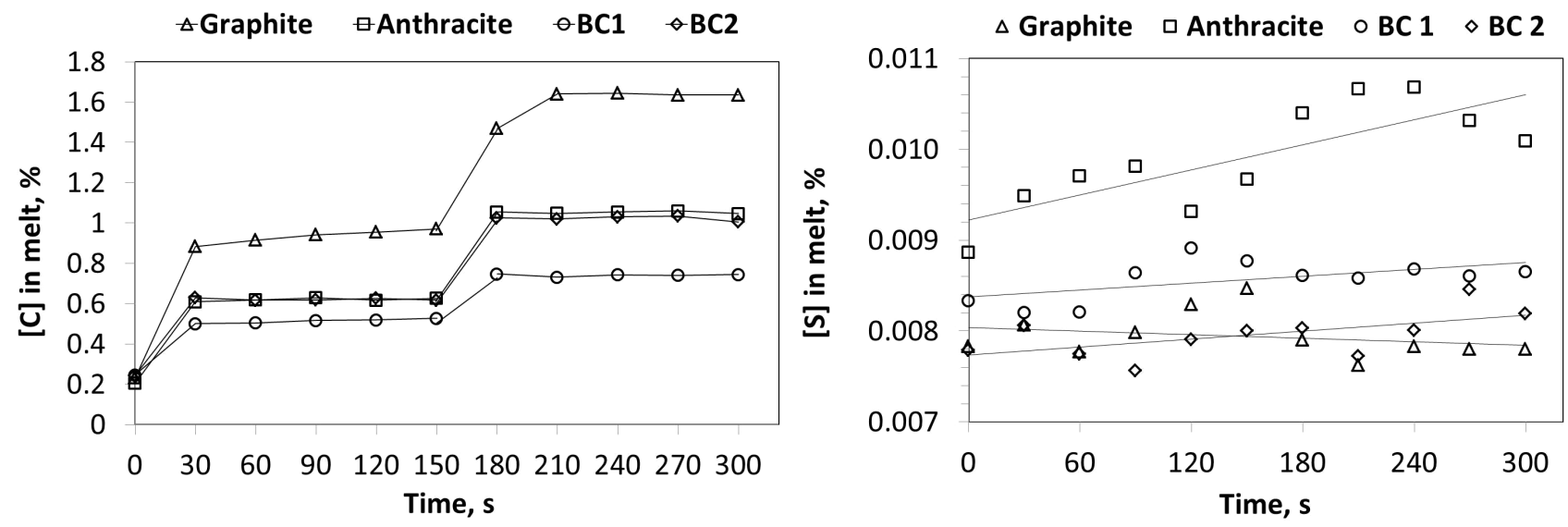

Fig. 5. Measured Carbon \& Sulphur contents in liquid iron over time during trials.
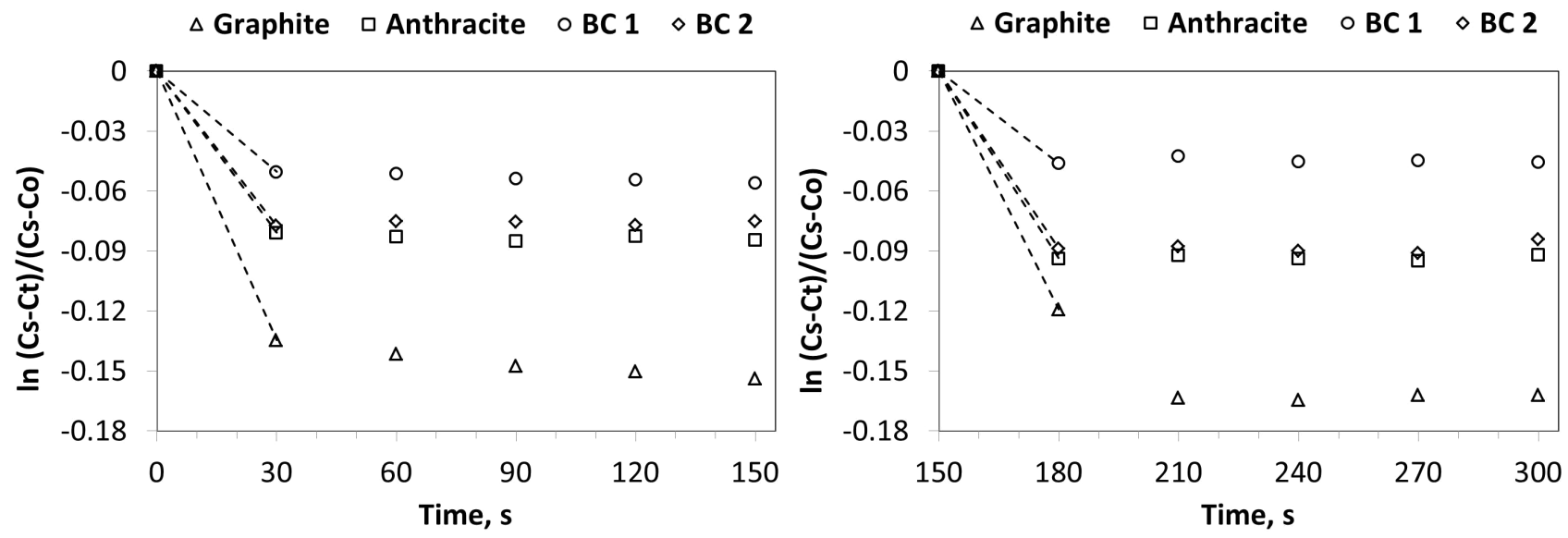

Fig. 6. $\ln [(\mathrm{Cs}-\mathrm{Ct}) /(\mathrm{Cs}-\mathrm{Co})]$ vs. time graphs for the first charge of 5 briquettes (left) and second charge (right).

Table 4. First order dissolution rate constants for different carbonaceous materials (fully immersed sample with forced convection conditions)

\begin{tabular}{ccccc}
\hline & $\mathrm{T}(\mathrm{K})$ & initial C\% & $\mathrm{k}^{\prime}\left(\times 10^{-4} \mathrm{~m} / \mathrm{s}\right)$ & Reference \\
\hline Graphite & 1875 & 1.5 & 1.96 & $(7)$ \\
Graphite & 1873 & 0.02 & 1.04 & $(10)$ \\
Graphite & 1823 & 2 & 2.49 & $(11)$ \\
Coke & 1845 & 2 & 2.31 & $(7)$ \\
Coke & 1823 & 2 & 1.00 & $(11)$ \\
Coke & 1873 & 1.5 & 1.43 & $(12)$ \\
Coke & 1873 & 1.5 & 1.07 & $(13)$ \\
Graphite & 1873 & 0.2 & 1.90 & Present work \\
Anthracite & 1873 & 0.2 & 1.31 & -“- \\
BC1 & 1873 & 0.2 & 0.72 & -“- \\
BC2 & 1873 & 0.2 & 1.25 & -“- \\
\hline
\end{tabular}

$\mathrm{dC} / \mathrm{dt}=\mathrm{K}(\mathrm{Cs}-\mathrm{Ct})$

where $\mathrm{Cs}(\mathrm{Cs}=5.412 \% \text { at } 1873 \mathrm{~K})^{11)}$ and $\mathrm{Ct}$ are the saturated carbon concentration and the actual carbon concentration at time $\mathrm{t}$ and $\mathrm{K}$ is the overall dissolution rate constant. Integrating Eq. (1) gives the following relationship,

$$
\ln (\mathrm{Cs}-\mathrm{Ct}) /(\mathrm{Cs}-\mathrm{Co})=-\mathrm{Kt} \text {. }
$$

where Co is the initial carbon concentration of the melt before addition of the carbonaceous test materials. The overall rate constant $\mathrm{K}$ can be solved by plotting $(\ln (\mathrm{Cs}-\mathrm{Ct}) /(\mathrm{Cs}-\mathrm{Co}))$ versus time, see Fig. 6. Furthermore, the first order dissolution rate constant $\mathrm{k}$ ' can be calculated from $\mathrm{K}$ with estimates of the interfacial contact area between briquettes and iron melt and the iron bath volume via,

$$
\mathrm{k}^{\prime}=(\mathrm{V} / \mathrm{A}) \mathrm{K} \text {. }
$$

As seen in Table 4, the present results are in good agreement with those reported in earlier studies. ${ }^{7,10-13)}$ In this study, Graphite has the highest dissolution rate followed by Anthracite, $\mathrm{BC} 2$ and $\mathrm{BC} 1$ respectively. A major difference between trials with Graphite compared to the other materials was that there were large amounts of black smoke generated when charging briquettes containing $\mathrm{BC} 1, \mathrm{BC} 2$ and Anthracite to the melt. As a long-chain hydrocarbon, the wax binder used in briquettes could explain this smoke generation via a rapid volatilization when charged to the melt; but considering that all briquettes contained the same amount of wax binder, i.e. $4 \mathrm{wt} \%$, and that graphite briquettes showed no smoke generation makes this explanation unlikely. Therefore, the observed smoke generation is thought to be due to the volatile contents in Anthracite, $\mathrm{BC} 1$ and $\mathrm{BC} 2$; see volatile contents in Table 1 . As a sidenote, the volatile contents in $\mathrm{BC} 1$ and $\mathrm{BC} 2$ are conceivably higher than one would expect when coking biochar at $1373 \mathrm{~K}$. A reason for this is the short residence times used during pilot-scale 
biochar production, not allowing sufficient time for more complete devolatilization in these specific biochar materials.

Consequently, it seems side reactions due to devolatilization during charging had a large effect on the yield of fixed carbon to the melt for the non-graphitic sources of carbon as seen in Fig. 7. These carbon yields are similar to results from Mourao et al. ${ }^{7)}$ where they observed 59\% carbon yield during dissolution of medium volatile coal particles injected into liquid iron-carbon alloy.

Interestingly, $\mathrm{BC} 2$ dissolution behavior in Fig. 6 is very similar to Anthracite while $\mathrm{BC} 1$ is much slower, roughly half that of the other two materials. Based solely on intrinsic carbon structure, the dissolution kinetics of Anthracite should be much faster than both biochars due to its inherent higher content of crystalline carbon. ${ }^{14)}$

In the case of $\mathrm{BC} 2$, it seems the lower inherent crystallinity of carbon content in this material is offset by a combination of higher porosity and lower ash content, compared to Anthracite, allowing for a greater degree of interfacial contact between carbon surfaces and iron melt giving comparable rates of carbon dissolution. The extent to which $\mathrm{BC} 2$ is more porous than Anthracite can be estimated by relating their true density from Table 1 to that for Graphite, see Eq. (4):

$$
\begin{aligned}
& \text { Porosity } \%= \\
& (1-(\text { true density sample / true density Graphite })) \times 100
\end{aligned}
$$

This analysis shows that Anthracite has 20.1\% open porosity while $\mathrm{BC} 2$ has $30.7 \%$, meaning $\mathrm{BC} 2$ has a porosity that is roughly 1.5 times greater than Anthracite. Therefore, the dissolution-limiting effect postulated by by Mourao et al., ${ }^{7)}$ i.e. where formation of islands of carbon-saturated iron due to entrapment in pores will hinder carbon dissolution from more porous materials, is not supported by this study. In comparison, the apparent dissolution of carbon from Anthracite is likely hampered by its much higher sulfur content compared to biochars, see Table 1. Higher sulfur contents in a dissolving carbonaceous material will lead to higher sulfur contents in the interfacial liquid boundary between solid particles and bulk iron melt thereby lowering the driving force for carbon dissolution into this boundary. ${ }^{15}$ ) As seen in Fig. 5, increasing sulfur contents in the melt were only clearly discerned for the trial with Anthracite.

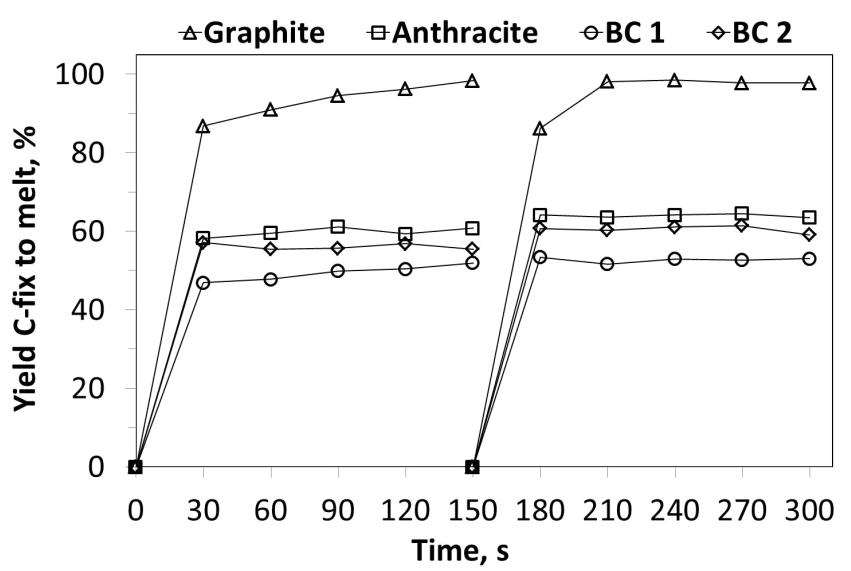

Fig. 7. Carbon yield during dissolution trials.
In the case of $\mathrm{BC} 1$, comparatively slower dissolution kinetics is attributed in-large to higher ash content than in BC2 and Anthracite, see Table 1. The inhibiting effect of inorganic matter content on carbon dissolution in liquid iron has been reported in numerous studies. ${ }^{16)}$ Important here is not only the yield of ash in $\mathrm{BC} 1$ but also the ash composition and its melting behavior, which defines to what extent a film of ash/slag can form on carbon surfaces inhibiting carbon dissolution. Table 5 shows the solid-liquid ratios of ash/slag at the interface for Anthracite, $\mathrm{BC} 1$ and $\mathrm{BC} 2$ compositions calculated using the Thermo-Calc software. ${ }^{17)}$ Here it is apparent that the ash/slag composition in $\mathrm{BC} 1$ is only $50-60 \%$ liquid between $1823-1873 \mathrm{~K}$ compared to $80-100 \%$ liquid for the other two test materials indicating a higher tendency for viscous slag formation at the interface between carbon and liquid iron.

\subsection{Large-scale Carburizing Test at Höganäs Halmstad}

With a promising result for biochar BC2 from lab-scale trials in hand, a preliminary test was performed in the $50 \mathrm{t}$ EAF at Höganäs Halmstad in order to access the feasibility of replacing part of the standard anthracite charge with biochar BC2. The total amount of carbonaceus materials added via bigbags in the first scrap bucket for each heat and the corresponding first carbon and sulfur analysis is presented in Table 6.

Carbon analyses for heats $2-5$ were essentially the same regardless if biochar was charged or not. The analysis for heat 1 deviates from the others because double the ordinary amount of carbon was charged by mistake, i.e. $600 \mathrm{~kg}$ via bigbags and $600 \mathrm{~kg}$ via pneumatic feeding. In heat 6 the

Table 5. Calculated solid-liquid ratios at 1823 and $1873 \mathrm{~K}$ for the ash compositions in Anthracite, BC1 and BC2.

\begin{tabular}{cccccccccc}
\hline & \multicolumn{2}{c}{ Anthracite } & & \multicolumn{2}{c}{ BC1 } & & \multicolumn{2}{c}{ BC2 } \\
\cline { 1 - 1 } \cline { 8 - 9 } $\begin{array}{c}\text { Temp. } \\
(\mathrm{K})\end{array}$ & $\begin{array}{c}\text { Solid } \\
(\%)\end{array}$ & $\begin{array}{c}\text { Liquid } \\
(\%)\end{array}$ & & $\begin{array}{c}\text { Solid } \\
(\%)\end{array}$ & $\begin{array}{c}\text { Liquid } \\
(\%)\end{array}$ & & $\begin{array}{c}\text { Solid } \\
(\%)\end{array}$ & $\begin{array}{c}\text { Liquid } \\
(\%)\end{array}$ \\
\hline 1823 & 7 & 93 & & 46 & 54 & & 21 & 79 \\
1873 & 0 & 100 & & 40 & 60 & & 10 & 90 \\
\hline
\end{tabular}

Table 6. Charge carbon amount and first carbon and sulfur analy-

\begin{tabular}{|c|c|c|c|c|c|}
\hline Heat & $\begin{array}{l}\text { Anthracite, } \mathrm{kg} \\
(3-15 \mathrm{~mm})\end{array}$ & $\begin{array}{c}\mathrm{BC} 2, \mathrm{~kg} \\
(0.1-6 \mathrm{~mm})\end{array}$ & $\begin{array}{c}\text { Total, } \\
\mathrm{kg}\end{array}$ & {$[\mathrm{C}] \%$} & {$[\mathrm{~S}] \%$} \\
\hline \multirow{3}{*}{$\begin{array}{c}\text { Average } \\
2018\end{array}$} & & & & Max. 0.249 & Max. 0.0111 \\
\hline & $600-800(\mathrm{pf})$ & & & Avg. 0.153 & Avg. 0.0097 \\
\hline & & & & Min. 0.058 & Min. 0.0082 \\
\hline $1^{*}$ & $600+600(p f)$ & & 1200 & 0.226 & 0.0119 \\
\hline 2 & 400 & 200 & 600 & 0.066 & 0.0110 \\
\hline 3 & 600 & & 600 & 0.067 & 0.0111 \\
\hline 4 & 400 & 200 & 600 & 0.065 & 0.0102 \\
\hline 5 & 600 & & 600 & 0.069 & 0.0095 \\
\hline 6 & 400 & 250 & 650 & 0.120 & 0.0082 \\
\hline
\end{tabular}
sis after meltdown.

*An extra charge of Anthracite via pneumatic feeding (pf) was charged by mistake 
charge of BC 2 was increased from 200 to $250 \mathrm{~kg}$ and the resulting carbon analysis was almost double that in heats 2-5. A $50 \mathrm{~kg}$ increase would not normally account for such a jump in carbon content. Furthermore, this behavior could be due to any a number of other inter-dependent variables that are difficult to precisely control in an industrial plant setting for example; carbon sampling routine, differences in scrap composition between heats, size of hot heel, oxygen injection, bath agitation and carbon charge location in the scrap bucket amoung others. Therefore, discerning a definitive reason for such a result is beyond the scope of this study.

Concerning the sulfur analyses, there was no significant trend between heats with and without $\mathrm{BC} 2$ to account for changes in the sulfur content of the different melts. In general, the trials performed using biochar as partical replacement of Anthracite charge showed no deviation from normal operation. As this was just a initial feasibility test for evaluating biochar behavior in the EAF, investigation of other parameters like carbon yield and energy consumption were beyond the scope of this trial.

\section{Conclusions}

Lab-scale carburizing trials showed that biochar $\mathrm{BC} 2$ had similar dissolution kinetics to high quality Anthracite coal. Contrary to common preconceptions, the properties of renewable woody biochar that differ the most from regular fossil-based carburizers; i.e. a lower carbon crystallinity and higher porosity common of biochars; do not necessarily constitute a disadvantage for biochar utilization as carburizer in steelmaking. Based on results from this study, a woody biochar with low ash content or a moderate ash content with optimal ash fusion properties, shows rates of carbon dissolution in liquid iron on par with the behavior of regular fossil-based carburizers such as anthracite or coke.

A successful trial with biochar as part of the charge carbon in the EAF was conducted at Höganäs Halmstad. Substitution of $1 / 3$ of the standard Anthracite carbon charge with biochar $\mathrm{BC} 2$ in three test heats showed no deviation from normal operating conditions.

This study is part of an on-going initiative to implement renewable carbon raw materials in Höganäs $A B$ 's iron and steelmaking processes. Future work will include investigations into combining biochar with fine-particulate scrap into composite agglomerates for more efficient recovery of iron and carbon units in the EAF.

\section{Acknowledgement}

We gratefully thank all colleagues at Höganäs Pilot Centre, Höganäs Halmstad Plant and Cortus Energy for their help during the course of this work.

\section{REFERENCES}

1) Swedish Environmental Protection Agency: Cooperation Objectives and Responsibilities, Sweden's Climate Act and Climate Policy Framework, http://www.naturvardsverket.se/klimatutslapp, (accessed 2019-12-12) (in Swedish).

2) Swedish Environmental Protection Agency: National Inventory Report Sweden 2019, Greenhouse Gas Emission Inventories 19902017, Swedish Environmental Protection Agency, Stockholm, (2019), 11.

3) E. Bellevrat and Ph. Menanteau: Rev. Metall. Paris, 106 (2009), 318.

4) T. Demus, T. Reichel, M. Schulten, T. Echterhof and H. Pfeifer: Ironmaking Steelmaking, 43 (2016), 564.

5) T. Norgate, N. Haque, M. Somerville and S. Jahanshahi: ISIJ Int., 52 (2012), 1472.

6) S. Orsten and F. Oeters: 5th Int. Iron and Steel Cong.: Proc. 6th Process Technology Conf., Vol. 6, Iron and Steel Society, Warrendale, PA, (1986), 143.

7) M. B. Mourao, G. G. Krishna Murthy and J. F. Elliott: Metall. Trans. $B, 24$ (1993), 629.

8) E. Pretorius, H. Oltmann and J. Jones: EAF Fundamentals, LWB Refractories, Hilden, (2010), 14.

9) R. Khanna, K. Li, Z. Wang, M. Sun, J. Zhang and P. S. Mukherjee: Char and Carbon Materials Derived from Biomass, ed. by $\mathrm{M}$. Jeguirim and L. Limousy, Elsevier, Amsterdam, (2019), 429.

10) D. Bandyopadhyay, S. D. Singh, D. Sanyal, K. K. Singh and K. N. Singh: Chem. Eng. J., 94 (2003), 79.

11) D. Jang, Y. Kim, M. Shin and J. Lee: Metall. Mater. Trans. B, 43 (2012), 1308.

12) H. Sun: ISIJ Int., 45 (2005), 1482.

13) H. Sun, K. Mori, V. Sahajwalla and R. D. Pehlke: High Temp. Mater. Process., 17 (1998), 257.

14) C. Wu and V. Sahajwalla: Metall. Mater. Trans. B, 31 (2000), 215

15) J. K. Wright and B. R. Baldock: Metall. Trans. B, 19 (1988), 375.

16) S. T. Cham: Ph.D. thesis, University of New South Wales, (2007), 41, http://handle.unsw.edu.au/1959.4/40685, (accessed 2019-10-15).

17) Slag 3-TCS Fe-containing Slag Database, Version 3.2, Thermo-Calc Software, Solna, (2012). 